First Peoples Child \& Family Review

An Interdisciplinary Journal Honouring the Voices, Perspectives, and Knowledges of First Peoples through Research, Critical Analyses, Stories, Standpoints and Media Reviews

\title{
Child Protective Services and University-Based Partnerships: A Participatory Action-Based Model for Creating and Sharing Knowledge
}

\author{
Randall L. Waechter, Christine Wekerle, Bruce Leslie, Deborah Goodman, \\ Nadine Wathen, Brenda Moody and MAP Research Team
}

Volume 4, Number 2, 2009

URI: https://id.erudit.org/iderudit/1069335ar

DOI: https://doi.org/10.7202/1069335ar

See table of contents

Publisher(s)

First Nations Child and Family Caring Society of Canada

\section{ISSN}

1708-489X (print)

2293-6610 (digital)

Explore this journal

Cite this article

Waechter, R., Wekerle, C., Leslie, B., Goodman, D., Wathen, N., Moody, B. \& MAP Research Team (2009). Child Protective Services and University-Based Partnerships: A Participatory Action-Based Model for Creating and Sharing Knowledge. First Peoples Child \& Family Review, 4(2), 118-128.

https://doi.org/10.7202/1069335ar

\section{Article abstract}

This paper presents one model for building and sustaining a research partnership between researchers and professional staff in child protection (CPS) agencies. The Maltreatment and Adolescent Pathways (MAP) study was designed to assess the health and well-being of the population of adolescents involved in the child welfare system of a major urban area. The study involved the collaboration between university based researchers and a range of child welfare staff, from administration to front-line workers. A key factor supporting collaboration was reciprocity with expertise, with CPS practitioner knowledge yielding intervention-relevant study queries and constructs, and researcher knowledge on health content and best practices yielding tailored training opportunities and increased climate for knowledge uptake. The MAP study combined a Participatory Action Research (PAR) model with a traditional, scientific positivist model, including the scientific elements of standardized measures, explicit evaluation of the participatory process, and research impact on the community members. This study: 1) provides information on the process of creating effective researcher-CPC agency partnerships, 2) considers key ethics issues, such as the participant's reactivity to research of child welfare- involved clients, and 3) examines the implications of implanting a PAR approach in research with Aboriginal CPS agencies, as per the required use of the Canadian Institutes of Health Research (CIHR) Guidelines for Health Research Involving Aboriginal People for future community- university partnerships.
Copyright @ Randall L. Waechter, Christine Wekerle, Bruce Leslie, Deborah Goodman, Nadine Wathen, Brenda Moody, MAP Research Team, 2009
This document is protected by copyright law. Use of the services of Érudit (including reproduction) is subject to its terms and conditions, which can be viewed online.

https://apropos.erudit.org/en/users/policy-on-use/ 


\title{
Ifilesit Peoples Child \& Samily Review
}

An Interdisciplinary Journal Honoring the Voices, Perspectives and Knowledges of First Peoples through Research, Critical Analyses, Stories, Standpoints and Media Reviews

\section{Child Protection Services and University-Based Partnerships: A Participatory Action-Based Model for Creating and Sharing Knowledge}

\author{
Randall L. Waechter ${ }^{a}$, ChrisAboritine Wekerle ${ }^{b}$, Bruce Leslie ${ }^{c}$, Deborah Goodman ${ }^{d}$, Nadine \\ Wathen ${ }^{e}$, Brenda Moody ${ }^{f}$, and the MAP Research Team ${ }^{g}$
}

${ }^{a}$ Child, Youth \& Family Program, Centre for Addiction and Mental Health, Toronto, Ontario, Canada.

${ }^{\mathrm{b}}$ McMaster University, Halifax, Ontario, Canada.

'Catholic Children's Aid Society of Toronto, Toronto, Ontario, Canada.

${ }^{\mathrm{C}}$ Children's Aid Society of Toronto, Toronto, Ontario, Canada.

e The University of Western Ontario, London, Ontario, Canada.

${ }^{f}$ Peel Children's Aid Society, Mississauga, Ontario, Canada.

${ }^{9}$ MAP Co-Investigators: Michael Boyle, Eman Leung, Harriet MacMillan, and Nico Trocmé.

\section{Introduction}

Childhood maltreatment is a recognized public health epidemic and a serious human rights concern, leading to increased demands for and strain on state intervention (World Health Organization, 2002). Maltreatment has broad-ranging impairments to health such as increased risk for obesity, mood and anxiety disorders, posttraumatic stress disorder, substance abuse, self-harm, dating violence, and risky sexual practices (Gilbert et al., 2009; MacMillan et. al., 2001; Wekerle, Leung, Goldstein,

Questions or correspondence concerning this article may be addressed to:

Child, Youth \& Family Program

Centre for Addiction and Mental Health

250 College Street

Toronto, Ontario, Canada

M5T 1R8

416-535-8501 ext. 6472 (phone)

416-979-4668 (fax)

randy waechter@camh.net

118

\begin{abstract}
This paper presents one model for building and sustaining a research partnership between researchers and professional staff in child protection service (CPS) agencies. The Maltreatment and Adolescent Pathways (MAP) study was designed to assess the health and well- being of the population of adolescents involved in the child welfare system of a major urban area. The study involved the collaboration between university-based researchers and a range of child welfare staff, from administration to front-line workers. A key factor supporting collaboration was reciprocity with expertise, with CPS practitioner knowledge yielding intervention-relevant study queries and constructs, and researcher knowledge on health content and best practices yielding tailored training opportunities and increased climate for knowledge uptake. The MAP study combined a Participatory Action Research (PAR) model with a traditional, scientific positivist model, including the scientific elements of standardized measures, explicit evaluation of the participatory process, and research impact on the community members. This study: 1) provides information on the process of creating effective researcher-CPS agency partnerships, 2) considers key ethics issues, such as the participant's reactivity to research of child welfare-involved clients, and 3) examines the implications of implanting a PAR approach in research with Aboriginal CPS agencies, as per the required use of the Canadian Institutes of Health Research (CIHR) Guidelines for Health Research Involving Aboriginal People for future community-university partnerships.
\end{abstract}

Thornton, \& Tonmyr, 2009; Wekerle, MacMillan, Leung \& Jamieson, 2008). Without maltreatment prevention and ameliorative intervention on impairment, adulthood adaptive functioning is seriously at risk; in a prospective study of substantiated maltreated children only $22 \%$ were deemed resilient in adulthood (McGloin \& Widom, 2001). To forge positive outcomes for child protection services (CPS) youth, research evidence on key target areas and underlying processes that can consider complex models is needed. There is a high need to assess the functioning and resilience among maltreated Aboriginal 


\begin{abstract}
Acknowledgements:
We acknowledge funding support from: Canadian Institutes of Health Research (CIHR) - Institute of Gender \& Health, Ontario Women's Health Council Mid-Career Award, The Centre of Excellence in Child \& Youth Mental Health at CHEO, Ontario Mental Health Foundation, and Ontario Ministry of Children and Youth Services. We thank the child protective service staff members of the MAP Research Advisory Board and the MAP youth for their participation and knowledge sharing. We acknowledge the valuable assistance of Maria Chen.
\end{abstract}

youth populations. Unique historical contexts require longitudinal study to document the extent and duration of trauma and chronic posttraumatic stress disorder (PTSD) symptomatology across Aboriginal generations (e.g., Wekerle, Bennett, \& Fuchs, 2009), as well as to consider the health funding and consequent health disparities among Aboriginal youth (e.g., UNICEF Canada Report on Aboriginal Children Health, 2009; see also FNCFCS site for Governor General Report information, www.fncfes. com).

Collaborations among Aboriginal CPS agencies, nonAboriginal child welfare, and child welfare researchers is essential to develop knowledge on the parameters of youth functioning, particularly given the context of inadequate funding for First Nations CPS agencies (e.g., Auditor General of Canada Report, May 2008), and over-representation of Aboriginal children in the CPS system (e.g., Blackstock, Trocmé, \& Bennett, 2004). Local context also needs to be taken into account in any research design and partnership model, given the findings that with greater localized governance structure in Aboriginal communities, there is higher youth resilience (e.g., Chandler \& Lalonde, 2008). As with non-Aboriginal CPS youth, the system history of the youth (e.g., number of home and school changes, often referred to as "turbulence"; Moore, Ehrle, \& Vandivere, 2000), and youth individual factors (e.g., Ordolis, 2007) are part of understanding where to target specialized services and prevention programming. Obtaining the data, though, is only one large step. There needs to be further research on how best to implement the knowledge and the observable impact on practice and youth functioning from the dissemination and uptake of the new research knowledge. To date, challenges remain on effective utilization of Aboriginal-specific research, and application to the local setting where child safety, practical support and treatment services are focal (e.g., Lafrance, 2009; Tonmyr, Jack, Brooks, Kennedy \& Dudding, 2009).

Child welfare resides in the wider community context, interacting with the social and political landscape, even though services work with one child, one family at a time. Canadian surveillance data reports that Aboriginal children are more likely to receive a classification of substantiated or suspected, rather than non-substantiated, maltreatment in child welfare investigations than non-Aboriginal child cases. Further, socioeconomic disadvantage is a key issue for these families, with a greater number of moves, unsafe housing, and lack of employment (Trocmé, Knoke, \& Blackstock, 2004). Historical factors for Aboriginal caregivers may be under-recognized (and under-treated): a higher proportion of child welfare-involved parents report being maltreated themselves as children as compared to non-Aboriginal caregivers. In a recent commentary, Chief Wayne Christian (2008) of the Cedar Research Project in British Columbia directs attention to this historical trauma, which ranges broadly, from separation from siblings, peers, family, community, and cultural attachments, as well as the direct maltreatment.

\section{The value of targeting adolescence}

Like the early years, adolescence is a window of opportunity for health promotion given the onset of a number of adult behaviours, such as intimate relationships, sexual activity, and substance use. In normative adolescence, there is an increase in problem behaviours, negative mood, and interpersonal conflict, with issues escalating to disorder levels, but usually limited to the transitional ages of adolescence (for a review, see Arnett, 1999; Harcourt, 2009). However, for others, adolescent impaired functioning prefaces long-term psychiatric disorders (e.g., Kessler, Demler, Frank, Olfson, Pincus, Walters et. al., 2005; Wekerle, MacMillan, Leung, \& Jamieson, 2008). Very little research is evident for adolescent development among Aboriginal youth in the CPS system. The need for such knowledge is underlined by brain research that highlights the development of higher-order functions (e.g., memory, problem-solving), and the strengthening of neural pathways (Glaser, 2000). Most critically for CPS youth, adolescence marks the chronological timeframe for the cessation of CPS support. For some Aboriginal communities, CPS is a main service provider and a conduit to other services. With CPS involvement often ending at age 16 or, in some cases, continuing to early adulthood, understanding adolescent issues is important to understanding planning for future success. Both CPS workers and academics have an investment in forging partnerships to increase the knowledge base on adolescents in the CPS system. Another point of urgency is that for youths in state care, the government is responsible for providing for their health and wellness 
planning, and needs to demonstrate minimally "good enough" parenting and protection from injury.

The current evidence-based interventions to support maltreated youths' well-being (Wekerle, Miller, Wolfe, \& Spindel, 2006) have not been developed for Aboriginal youth, with notable exception in Canadian Aboriginal youth substance abuse prevention (Mushquash, Comeau, \& Stewart, 2007; Zahradnik, Stevens, Stewart, Comeau, Wekerle, \& Mushquash, 2007). A major factor - the lack of timely, relevant, and accessible data - can be supported by effective community-university collaboration. Issues such as CPS youth characteristics, opportunities for developmentally-timed intervention, treatment initiation, adherence and sequencing (e.g., co-morbidities, such as mental health and substance abuse), developmental health promotion (e.g., productive leisure, adaptive coping with stress, transitioning to independent living, etc.), and long-term outcomes in broad-based achievement require a sustained partnership, dedicated to on-going quality assurance and development via research. Currently, the evidence base for CPS practice and policy is limited by the minimal standardized information on its teen clients.

There is also an acknowledged cost to not conducting research with Aboriginal youth, in not having their voices heard in a compelling way. Becker-Blease and Freyd (2006) provide several examples of how the inclusion of maltreatment information has significant impacts on causal models of clinical syndromes, as well as the efficacy of treatment programs. Thus, if maltreatment is not included in research predicting resilience and impairment, its contribution and impact on developmental processes will remain like a missing puzzle piece. Finally, youth may approach research as an opportunity (e.g., Becker-Blease \& Freyd, 2006). In one research study, most youth who reported childhood maltreatment indicated that the research study was the first time that they disclosed their maltreatment history (Pearce et. al., 2008). While CPS youth involvement in research is complicated by age of consent issues, variations in caregivers, maltreatment and other critical disclosure issues (i.e., suicidality, homicidality), providing selfreport on one's life experiences is consistent with a narrative focus within current Aboriginal reconciliation initiatives (e.g., Dussault, 2007; Stewart, 2009) . Collaborative models of developing and executing research can serve to resolve some of these issues.

Many academics follow a positivist approach, which tends to contextualize science within controlled conditions rather than real world, day-to-day activities (Reason \& Bradbury, 2001). Research that can readily translate to day-to-day CPS practice requires partnership, as practice credibility does not rest solely on rigorous research design and statistical analyses (Leslie, 2005). It must include "communicative validity," where knowledge is constructed by equal contributors, as well as "pragmatic validity," where the goal of research is productive change (Kvale, 2002). In the best-case scenario, a sustained research partnership moves from research question identification (What do we want to know?) to study conceptualization (How do we assess it?) to clinical education (What training needs to happen?) to knowledge translation implementation research (How best to fan out study information, results, and implications for practice?) to impact evaluation to support practice change (How has a CPS system changed? How has caseworker behaviour changed? What measurable client change has occurred due to this knowledge?). Partnership supports "a bridge between academic concerns about validity and more reflexively practical questions" (Bradbury \& Reason, 2001, p. 447).

Participatory Action Research (PAR) serves as a useful starting point for such a bridge. PAR is defined as "a participatory, democratic process concerned with developing practical knowing in the pursuit of worthwhile human purposes, grounded in a participatory worldview" (Reason \& Bradbury, 2001, p. 1). The PAR model depends on community participation and ownership from study inception, as well as serving to create a network of practitioners, service recipients, and academics around a focal issue. It is nested, therefore, within a team-based learning model. PAR features, such as the inclusion of different ways of knowing, may be integrated with the traditional positivist model in allowing for both broader generalizations and practice-relevant knowledge (e.g., Teram, Schachter, \& Stalker, 2005). Further, potential stumbling blocks, such as ethics, where no clear, consistent guidelines exist for child welfare research, can be resolved with collaborative problem-solving.

A growing number of services are being provided either by fully mandated Aboriginal agencies or by Aboriginal counseling services that work in conjunction with mandated services to reach Aboriginal families living on or off reserve (Blackstock, 2003). Any research involving Aboriginal people will involve the sharing of some cultural knowledge, practices and/or traditions, even when these are not the subjects of the study, as they provide necessary context. Researchers need to recognize the importance of identifying the appropriate authorities representing the community in the development of the research project. Aboriginal communities in Canada have distinct political, legal, and cultural governance structures that have political legitimacy and that support their jurisdictional and decision-making authority on a broad spectrum of issues, including health. When approaching Aboriginal CPS for partnership, broad consultation and budgeted resources for such consultation need to be considered. This may involve, for example, translating 
publications, reports, and other relevant documents into the language of the Aboriginal community in the research. One route may include co-ownership of all processes and data, which is consistent with the Aboriginal concept of community (e.g., Stewart, 2009). The key issue is that the specifics about the data are clearly articulated (e.g., Memorandum of Agreement or Data-Sharing Agreement) and reflect a shared vision of research project goals. As CPS agencies are approached by research groups or initiate a research project, clear direction on the processes of research, internal ethics options, and models of successful research partnerships may be helpful. It is acknowledged that most workers in child welfare regard research as valuable (Mullen, 2004), yet it is also true that little statistical treatment of the substantial local data collection is published by CPS agencies.

To assist, the Canadian Institutes of Health Research (CIHR) has developed guidelines for conducting health research involving Aboriginal people (http://www. cihr-irsc.gc.ca/e/29134.html). Specifically, Article 3 of the guidelines state that "Communities should be given the option of a participatory-research approach". Here, we argue that a PAR model is the most effective way to conduct complex research, and utilize one study of CPS youth, as an illustrative example that could be applied to the Aboriginal context. The Maltreatment and Adolescent Pathways (MAP) Project (Wekerle et al., 2009) has youth self-report ethnic diversity (about a third report multiple ethnicities, including $8 \%$ of youth reporting at least partial Aboriginal heritage). The academics were scientist-practitioners drawn from paediatrics, child psychiatry, child and adult clinical psychology, and social work disciplines, with research expertise in epidemiology, theory-driven quantitative research design, and standardized clinical testing. Research with minors (i.e., youth are between 14 and 17 at the outset of the MAP), and targeting the full range of CPS statuses, created novel opportunities for identifying joint solutions to ethics issues, identifying useful steps and barriers to a collaborative, interdisciplinary, and cross-agency research partnership, as well as provide answers to fundamental questions about feasibility of a large-scale research project. In this paper, we discuss specific examples of how a PAR model was used to implement the MAP study and consider how it may apply to research with Aboriginal CPS youth.

\section{Bootstrapping the framework: Developing a Participatory Action-Based Model for CPS Research}

Front-line care workers most vividly see the challenges of daily living and building a healthy life trajectory faced by CPS youth. CPS staffers have observations of clinical trends and can guide the development of research questions. In the process sharing expertise, practitioners and researchers develop a shared language, leading to fewer requirements for "translation" than may be the case in other clinical areas (Leslie, 2005). We examine the implementation of a PAR research model by focusing on two salient issues in conducting collaborative research: (1) the process of developing a researcher-agency partnership, and (2) the ethical issues in CPS youth research. First, we briefly review the methods that were utilized to assess the use of a PAR model in the MAP study.

The use of a PAR model in the MAP study was examined via four evaluations completed by CPS agency workers on the MAP study research advisory board. PARspecific instruments to measure the partnering process were not readily available; PAR emphasized process more than its measurable indicators when the MAP feasibility study was initiated in 2001 (the MAP feasibility study spanned 2001-2003; the MAP longitudinal study continues data collection with CPS youth). Thus, a brief study-developed questionnaire asked about elements of the PAR process, such as perceptions of institutional support, and increases in research communications within the agency. Community agencies need to be clear about the checks and balances in the research procedures to ensure their youth clients are not being harmed by the research, although clear individual benefits may not be present either. The issue of reactivity to a research questionnaire that included sensitive topics, such as the history of maltreatment, was examined with a studydeveloped questionnaire, modelled after depression and HIV research. The youth participants in the MAP feasibility study completed a series of Likert-scale ratings at the outset of testing and again at the end of the MAP questionnaire. Two questions at the end of the questionnaire queried about once having participated in the research, would the youth's decision to participate have remained the same.

CPS agency workers $(n=28)$ who were on the MAP advisory board over the time of the MAP Feasibility study were nominated by participating CPS agencies' quality assurance or research-affiliated staff based on their perceived: (1) familiarity with and investment in research; (2) credibility within the CPS agency; (3) likeability by peers; and (4) level of knowledge or experience of child welfare practice. Seventy-five percent of the advisory board members were female, most (64\%) were between ages 40 to 59 . Most (82\%) completed at least a MSW degree. Forty-five percent of the respondents were frontline workers and 55\% supervisors or administrators. The mean number of CPS workers in the agency the respondents belonged to was $317(\mathrm{SD}=200)$. The advisory group met monthly with 
researchers, with pre-listed meeting agendas, circulated minutes, and a list-serve to support e-communications. Formal meetings facilitated the research project development in systematic ways, allowed for joint monitoring and problem-solving of research issues, the ready transmission of relevant research information (e.g., recruitment statistics), research-based continuing education, provision of topical empirical journal articles, and special events collaborations (e.g., practice journal special issue, research conference presentations, clinical research-based training). Each advisory board member was approved by their agency administration for their research time contributions, which was minimally five hours/month. As part of the MAP study, agencies received a $\$ 500$ honorarium for every 10 youth identified who were eligible (but not necessarily consenting to participate in the study). While youth were randomly selected from active caseload lists, the agencies needed to further consider whether youth met eligibility criteria, such as no significant developmental delay, no emergency psychiatric or residential issues, etc. CPS agencies provided meeting rooms at no cost and the research team provided refreshments at all meetings. Flexibility in board membership term and in role sharing was adopted. CPS staffers on the advisory board were responsible for maintaining an on-going profile of the study within their agency, updating in meetings, facilitating articles in agency newsletter and e-notices, and for co-presenting on study-related topics. Researchers were responsible for co-presenting on the study at CPS agencies, maintaining record-keeping and obtaining confidentiality agreements from researchers.

In the collection of data for the MAP study, the CPS caseworker was the first point of contact with the youth regarding the research opportunity. The CPS caseworker did not obtain study consent from the youth to participate in the study, as this may have been viewed as coercive. Instead, the caseworker briefly explained the study and asked the youth if a MAP research staff member could contact him/her (i.e., consent for the MAP Research Team to contact by phone and explain the research opportunity). If the youth agreed, his/her information was forwarded to the MAP research office and the CPS worker completed a brief form of youth background information. Youth were remunerated monetarily based on youth minimum wage and the longest time to questionnaire completion during focus group testing (which was 4.0 hours, with an average of 2.5 hours). Youth were given breaks and refreshments. Youth provided their own consent if aged 16 and above, and legal guardians provided consent if the youth was under age 16 . Youth and consenting guardians retained a copy of the consent form, with institutional and principal investigator contact information. Youth were provided with a help sheet with a range of online and local support services, as well directed to their caseworker with any research questions or if later having uncomfortable feelings. Most youth elected to complete the testing in their residence, if there was a private area available. If not, youth were tested at CPS agencies or at the research site (a public hospital) or community facility.

\section{Assessing the Effectiveness of the Partnership Process in the MAP Study}

Researchers, CPS staff members, and youth were involved in different stages of the study design (see Table 1). Specifically, CPS workers were involved as active partners from the first stages of study planning to dissemination efforts. CPS youth were consulted on wording and item inclusion in the questionnaire package as part of focus group testing for the MAP study questionnaire instrument. We evaluated CPS worker involvement in the MAP study by administering a participatory action questionnaire every three months during the monthly meeting period of the MAP Advisory Board. This questionnaire included items such as "How collaborative has this project been?" and "Have you felt your contributions were taken into consideration by the group?" Responses were averaged over time (see Table 2). Overall, CPS agencies reported that the research study was relevant, educational, collaborative, beneficial to CPS youth, and took relatively little time to implement. Importantly, $90 \%$ of the workers believed that the workload for the project was not too heavy. In applying this to Aboriginal CPS, one must note the context of service under-funding and the fact that such research partnership involves non-service staff time. The MAP presents a shared-resource model that may not be appropriate for small or funds-strapped agencies. While an honorarium system was finally agreed upon, earlier considerations were worker time backfill and research honoraria.

\section{Assessing the Effectiveness of Resolving Ethical Issues in the MAP Study}

Protecting youth confidentiality was a paramount concern for the CPS agencies. To this end, all MAP research team members completed CPS agency confidentiality agreement forms. When agency case lists were forwarded to the MAP research team, they contained limited information (e.g., youth date of birth, CPS identification number, youth caseworker). An anonymous data collection system was developed, where a computer program links youth data via a one-way encryption process. In this process, each youth participant is assigned a MAP Project ID number that the testing staff used to tag the youth's responses on all of the MAP questionnaires. Youth completed the questionnaires on laptop computer. 
Responses are uploaded to the secure MAP database in real time via cellular internet connection. As such, youth data is linked longitudinally and can be downloaded from the database at any time - when downloaded, all identifying information is removed from the data by a proprietary software program. As such, external researchers who analyze the MAP data do not have access to the youth's name, date of birth, address or any other identifying information and MAP Project data collection staff who do have access to the youth's name, phone number, address, MAP ID number etc. do not have access to the data. Thus, sensitive identifying information is "split" from the youth's responses to the questionnaires. Youth identification can never be paired with the youth's study responses.

The youth who participated in the MAP were paid cash remuneration for their time. Since this is not standard practice for research with minors, CPS agency support was required for the academic research ethics clearance. The CPS agencies provided a letter to the research institution ethics board arguing for a monetary remuneration that resembled youth employment. The CPS agencies' intent was to reinforce to youth an appropriate (legal) means of acquiring funds. To avoid coercion within this employment context, the youth were advised both verbally and in writing of the voluntary nature of research, that they had the right to refuse to respond to any uncomfortable question, and that they had the right to withdraw from the research without explanation, and that the research was completely separate from CPS services. The research procedures and consent forms were written by the researchers under the advisement of the CPS advisory board, and the CPS agency lawyers reviewed the university research ethics submission. Thus, prior to the academic research process, CPS agency clearance was obtained, which would be consistent with the CIHR guidelines of needing to demonstrate in any grant application, Aboriginal community approval in writing and explication of meaningful stakeholder engagement in the research project, from start to finish.

Another key concern was youth reactivity to sensitive research questions about maltreatment history, sexual activity, substance use etc. We addressed this concern by examining the results of questions that were included at the beginning and end of the MAP questionnaire package. An analysis of youth responses to these items at the initial time point $(\mathrm{N}=500$, Mean age $=15.85[\mathrm{SD}=$ 1.02 ], 47.7\% male, 61\% Crown Wards, 18\% Community Families, 15\% Society Wards, and 6\% Temporary Care) indicates that youth do experience some minor stress and discomfort in completing the MAP questionnaire package (see Table 3). For instance, youth reported being significantly less relaxed after $($ Mean $=4.05, \mathrm{SD}=1.63)$, as opposed to prior to filling out the MAP questionnaire,
$($ Mean $=4.44, \mathrm{SD}=1.29 ; \mathrm{t}=5.21, \mathrm{p}<.001)$. Youth reported decreases in feeling happy, finding it less easy to breathe, and having a lower energy level after filling out the questionnaires. Finally, youth report higher levels of distress after filling out the questionnaire (pre Mean = $1.86, \mathrm{SD}=1.69$; post Mean $=2.12, \mathrm{SD}=1.93 ; \mathrm{t}=-2.96$, $\mathrm{p}<.01)$ as well as greater muscle tenseness after filling out the questionnaire (pre Mean $=2.22, \mathrm{SD}=1.88$; post Mean: 2.46, $\mathrm{SD}=2.02 ; \mathrm{t}=-2.53, \mathrm{p}=.01)$. While these results demonstrate statistically significant differences, it is important to note that post-questionnaire levels reported by the youth were still at or above the halfway mark (3.5) on the scale and that, numerically, all of the statistically significant changes in youth ratings were relatively small. It is also important to note that none of the youth who have participated in the MAP study have required follow-up services for distress or counselling following the completion of the MAP questionnaire package. All MAP testing staff are trained to carefully monitor for symptoms of distress and end the study or intervene in an appropriate manner (i.e., call CAS intake, MAP Principal Investigator, collaborate with Group Home/Foster Home guardians). Finally, four questions were asked at the end of the MAP questionnaire to survey youths' overall experience with the research. The CPS youth responded positively to the question, "How interesting did you find these study questions?" with a mean response of 4.00 $(\mathrm{SD}=1.57)$ on a scale of 0 (Not at all) to 6 (A lot); youth also respond somewhat positively to the statement "I gained something by filling out this questionnaire", with a mean response of $3.53(\mathrm{SD}=1.75)$ on a scale of 0 (Not at all) to 6 (A lot). Youth indicated that completing the questionnaire did not upset them more than they expected (Mean $=0.91, \mathrm{SD}=1.59)$. Finally, when asked if they would still have agreed to take part in the study after completing the questionnaires, the average response was $4.55(\mathrm{SD}=1.72)$ on a scale of 0 (Not at all) to 6 (A lot.). Thus, the youth show some measurable distress, but also measurable positive value to the research participation. In the cost-benefit analysis, youth tolerate the study sufficiently to warrant obtaining this novel information on CPS youth health.

The mixed positivist / PAR methodological model utilized in the MAP study has incorporated different "ways of knowing." CPS practice knowledge is valued across the research phases, from input into the specific questionnaire content based on observation of clinical trends, to input on dissemination products. The positivist contribution is to utilize the published measurement literature in addressing content areas of interest. CPS staff were directly assessed on their experiences with PAR, in providing ratings to a common set of questions. A combined PAR and positivist approach would seem to meet the needs of both CPS staffers and academic 


\section{Child Protective Services and University-Based Partnerships}

researchers and seems compatible in utilizing CIHR guidelines for research with Aboriginal populations. The growth of quality assurance and quality improvement programs have also highlighted the benefits of adapting research methodologies in service organizations to better meet the need to monitor effectiveness and efficiency of service provision more closely (Leslie, 2005). We believe that this combined PAR/positivist research approach will not only be effective, but critical in conducting research with Aboriginal CPS agencies given the unique cultural and social background among many of the children and families in care. As Stewart (2009) reports in her quest to incorporate Western scientific and Native ways of knowing in Native health research: "....it is understood that research with Indigenous communities requires a different paradigm than has been historically offered by academic researchers. Research methodologies employed in Native contexts must come from Indigenous values and philosophies for a number of important reasons and with consequences that impact both the practice of research itself and the general validity of research results" (p. 57). Based on our experience with the MAP Project and the CIHR Guidelines, we review six points that should be considered when conducting an Aboriginal CPS research study. These are as follows.

1. Researchers need to understand and respect Aboriginal world views, including responsibilities to the people and culture that flow from being granted access to traditional or sacred knowledge. This means accepting a responsibility to be accountable to the CPS agencies for the knowledge generated in the research process. While researchers have a responsibility to be accountable to any CPS agency with which they have partnered, understanding Aboriginal world views and culture needs to be incorporated into the research design and investigators should allow extra time and resources to explore and understand these worldviews. For example, traditional Aboriginal world views are based on respect for all life forms as literally conscious and intrinsically interdependent and valuable (Corsiglia \& Snively, 1997). As such, research on Aboriginal CPS children and youth health might incorporate measures that examine the youth's relation not only to parents, caregivers, friends, and community members, but also nature, such as animals, plants, and landscapes. These types of questions may be important variables in understanding Aboriginal health outcomes.

2. Community's jurisdiction over the research means planning the time for a partnership development process. This process may begin with determining whether the Aboriginal community manages and controls health matters or whether an outside government agency has jurisdiction. Thus, researchers need to become familiar with any by-laws, policies, rules and procedures adopted by the community. Including Aboriginal CPS children and youth in the design and implementation of the research may be an opportunity for social engagement. For example, guidelines for the meaningful engagement of youth in Canadian organizations are available on the First Nations Child \& Family Caring Society homepage: (http://www.fncfcs.com/projects/ ethicalYouthEngagement.php).

3. Ethical principles of Aboriginal health research need to be understood in the context of Aboriginal concepts such as sacred space, sacred knowledge, and traditional knowledge. There may be a need to develop research tools to reflect and capture this perspective as a context to Aboriginal youth wellbeing. Ethical principles familiar to a researcher, such as autonomy and critical evaluation, need to be re-considered within the research partnership to harmonize with the values and beliefs of the Aboriginal community. The research team can share expertise in how to set up a research ethics board and provide commentary on community-developed research protocols.

4. Aboriginal societies are traditionally oral societies and written consent forms may be contrary to respecting Aboriginal approaches to research initiatives. Oral consent may be an appropriate alternative to obtaining written consent, but there needs to be a research team documentation of the practice. University research ethics boards are prepared to consider unique cases that vary from the typical procedure, however, these arguments need to be demonstrated to be part of the partnership process, based on agreement, as well as preliminary research. One possibility is for the researcher to obtain oral consent from the participant and document this consent in written form and have this written form notarized by both the researcher and a third-party witness.

5. Researchers need to make efforts to share the results of the research with the wider Aboriginal community, in venues that are most suitable to the knowledge recipients that allow for discussion and on-going relationship-building and access to expertise. Researchers should also work to foster education and training of community members to enhance their participation in the research project, including, where possible, employing community members. Researchers should budget the necessary time and resources to train and supervise Aboriginal CPS staff in conducting research, as needed, with a view to capacity-building through partnering. 
6. The broader Aboriginal community, as with the CPS partners, should have the opportunity to review the research results before they are submitted for publication, to ensure appropriate context, the limits to the research, and to identify future directions. This may include setting up presentations to the community members and soliciting oral feedback. Researchers should budget both time and monetary resources to give presentations to the Aboriginal community and revise results based on feedback.

In sum, the dissemination of models of conducting research and standard guidelines and expectations for public funding of research on Aboriginal populations is as important as the actual health research knowledge identified. A combination of a PAR and positivist traditions may facilitate that the highest quality research is available for evidence-based advocacy for practice and policy change to remediate Aboriginal service funding disparities. Such research partnership may provide the context for sustained rigorous and relevant research required for quality services and equality in health outcomes for Aboriginal child welfare-involved youth.

\section{References}

Arnett, J. J. (1999). Adolescent storm and stress, reconsidered. American Psychologist, 54 (5), 317-326.

Auditor General of Canada Report (May 2008). Chapter 4 - First Nations Child and Family Services ProgramIndian and Northern Affairs Canada. Downloaded from http://www.oag-bvg.gc.ca/internet/English/parl oag_200805_04_e_30700.html on September 2, 2009.

Becker-Blease, K. A. \& Freyd, J. J. (2006). Research participants telling the truth about their lives. American Psychologist, 61, (3), 218-226.

Blackstock, C. (2003). First Nations Child and Family Services: Restoring peace and harmony in First Nations communities. In Kufeldt, K. and McKenzie, B. (Eds.). Child Welfare: Connecting Research, Policy and Practice. Waterloo: Wilfrid Laurier Press, 331-343.

Blackstock, C., Trocmé, N., \& Bennett, M. (2004). Child maltreatment investigations among Aboriginal and nonAboriginal families in Canada. Violence Against Women, 10(8), 901-916.

Bradbury, H., \& Reason, P. (2001). Conclusion: Broadening the bandwidth of validity: Issues and choicepoints for improving the quality of action research. In P. Reason \& H. Bradbury (Eds.), Handbook of Action Research (pp. 447-455). London: Sage.

Chandler, M.J. \& Lalonde, C.E. (2008). Cultural continuity as a protective factor against suicide in First Nations youth. Horizons. 10(1), 68-72.

Corsiglia, J. \& Snively, G. (1997). Knowing home: NisGa'a traditional knowledge and wisdom improve environmental decision making. Alternative Journal, 23 (3), 22-27.
Christian, W. M., \& Spittal, P. M. (2008). The Cedar Project: Acknowledging the pain of our children. The Lancet, 372 (9644), 1132-1133.

Dussault, R. (2007). Indigenous peoples and child welfare: The path to reconciliation. First Peoples Child \& Family Review, 3 (3), 8-11.

Gilbert, R., Kemp, A., Thoburn, J., Sidebotham, P., Radford, L., Glaser, D., \& MacMillan, H. L. (2009). Recognising and responding to child maltreatment. Lancet, 373 (9658), 167-180.

Glaser, D. (2000). Child abuse and neglect and the brain. Journal of Child Psychology and Psychiatry, 41(1), 97-116.

Harcourt, H. F. (2009). Review of helping adolescents at risk: Prevention of multiple problem behaviors. Child \& Adolescent Social Work Journal, 26 (3), 279-281.

Kessler, R. C., Demler, O., Frank, R. G., Olfson, M., Pincus, H. A., Walters, E. E., Wang,P., Wells, K. B., \& Zaslavsky, A. M. (2005). Prevalence and treatment of mental disorders, 1990 to 2003. New England Journal of Medicine, 352, (24), 2515-2523.

Kvale, S. (2002). The social construction of validity. In N. K. Denzin \& Y. S. Lincoln (Eds.), The Qualitative Inquiry Reader (pp. 299-325). Thousand Oaks, CA: Sage.

Lafrance, J. (2009). Commentary: Knowledge mobilization for the real world - seeking wisdom. First Peoples Child \& Family Review, 4, 80-88.

Leslie, B. (2005). Creating and sustaining research partnerships between academic institutions and service agencies. Ontario Association of Children's Aid Societies Journal Special Edition: Research in Child Welfare, 49, 1, $26-34$.

MacMillan, H. L., Fleming, J. E., Streiner, D. L., Lin, E., Boyle, M. H., Jamieson, E., Duku, E. K., Walsh, C. A., Wong, M. Y.-Y., \& Beardslee, W. R. (2001). Childhood abuse and lifetime psychopathology in a community sample. American Journal of Psychiatry, 158 (11), 1878-1883.

McGloin, J. M. \& Widom, C. S. (2001). Resilience among abused and neglected children grown up. Development and Psychopathology, 13, 1021-1038.

Moore, K. A., Ehrle, J., \& Vandivere, S. (2000). Turbulence and child well-being. Policy Publication Series B, No. B-16. The Urban Institute: Washington, DC.

Mullen, E. (2004). Facilitating practitioner use of evidencebased practice. In Roberts, A. R. \& Yeager, K.R. (Ed.), Evidence-based practice manual: Research and outcome measures in health and human services. (pp. 205 -218). New York: Oxford University Press.

Mushquash, C. J., Comeau, N. M., \& Stewart, S. H. (2007). An alcohol abuse early intervention approach with Mi'kmaq adolescents. The First Peoples Child and Family Review, 3(1), 17-26.

Ordolis, E. (2007). A story of their own: Adolescent pregnancy and child welfare in Aboriginal communities. First Peoples Child \& Family Review, 3 (4), 30-41. 


\section{Child Protective Services and University-Based Partnerships}

Pearce, M. E., Christian, W. M., Patterson, K., Norris, K., Moniruzzaman, A., Craib, K. J. P., Schechter, M. T., \& Spittal, P. M. (2008). The Cedar Project: Historical trauma, sexual abuse, and HIV risk among young Aboriginal people who use injection and non-injection drugs in two Canadian cities. Social Science \& Medicine, 66, 2185-2194.

Reason, P., \& Bradbury, H. (Eds.). (2001). Introduction: Inquiry and participation in search of a world worthy of human aspiration. In P. Reason \& H. Bradbury (Eds.), Handbook of action research (pp. 1-14). London: Sage.

Stewart, S. L. (2009). One indigenous academic's evolution: A personal narrative of Native health research and competing ways of knowing. First Peoples Child \& Family Review, 4 (1), 57-65,

Teram, E., Schachter, C. L., \& Stalker, C. A. (2005). The case for integrating grounded theory and participatory action research: Empowering clients to inform professional practice. Qualitative Health Research, 15, 8, 1129-1140.

Tonmyr, L., Jack, S., Brooks, S., Kennedy, B., \& Dudding, P (2009). Utilization of the Canadian Incidence Study of Reported Child Abuse and Neglect in First Nations Child Welfare Agencies in Ontario. First Peoples Child \& Family Review, 4, 38-46.

Trocmé, N., Knoke, D., \& Blackstock, C. (2004). Pathways to the overrepresentation of Aboriginal children in Canada's child welfare system. Social Service Review, 78, 577- 599.

UNICEF Canada report on Aboriginal Children's Health. Downloaded from http://www.unicef.ca/portal/Applications/Core/ sbNews/sbNews.aspx? NewsID $=597 \& a m=2782 \& \mathrm{rp}=126$ on September 4, 2009.

Wekerle, C., Bennett, M., \& Fuchs, D. (2009). Editorial: The legacy of a child: Jordan's principle. First People's Child \& Family Review, 4, 5-7.

Wekerle, C., Leung, E., Goldstein, A., Thornton, T., \& Tonmyr, L. (2009). Up against a wall: Coping with becoming a teen. (Substance use among adolescents in child welfare versus adolescents in the general population: A comparison of the Maltreatment and Adolescent Pathways [MAP] longitudinal study and the Ontario Student Drug Use Survey [OSDUS] datasets). London, ON: University of Western Ontario.

Wekerle, C., Leung, E., MacMillan, H.L., Boyle, M., Trocmé, N., \& Waechter, R. (2009). The impact of childhood emotional maltreatment on teen dating violence. Journal of Child Abuse \& Neglect.

Wekerle, C., MacMillan, H.L., Leung, E., \& Jamieson, E. (2008). Childhood maltreatment. In M. Hersen \& A. M. Gross (Eds.), Handbook of clinical psychology, Vol. 2, Children and adolescents (pp. 856-903). Hoboken, NJ: John Wiley \& Sons.

Wekerle, C., Miller, A. L., Wolfe, D. A., \& Spindel, C. B. (2006). Childhood Maltreatment.

Ashland, OH: Hogrefe \& Huber.

Wekerle, C., \& Wolfe, D. A. (2003). Child maltreatment. In E. J. Mash \& R. A. Barkley (Eds.),
Child Psychopathology (2nd Edition), pp. 632-686). New York, NY: Guilford Press

Widom, C. S. (1999). Posttraumatic stress disorder in abused and neglected children grown up. American Journal of Psychiatry, 156, 1223-1229.

World Health Organization. (2002). World report on violence and health, Geneva.

Zahradnik, M., Stevens, D. S., Stewart, S. H., Comeau, N. M., Wekerle, C., \& Mushquash, C. (2007). Building a collaborative understanding of pathways to adolescent alcohol misuse in a Mi'kmaq community: A process paper. The First Peoples Child and Family Review, 3(2), 27-36.

Table 1. Involvement of Researchers, CPS Staff, and CPS Youth in the Development of the MAP Study.

\begin{tabular}{|l|c|c|c|}
\hline Research Process & Researchers & $\begin{array}{l}\text { CPS } \\
\text { Staff }\end{array}$ & $\begin{array}{l}\text { CPS } \\
\text { Youth }\end{array}$ \\
\hline $\begin{array}{l}\text { Development of } \\
\text { research questions }\end{array}$ & $\mathrm{X}$ & $\mathrm{X}$ & \\
\hline $\begin{array}{l}\text { Selection of } \\
\text { participants }\end{array}$ & $\mathrm{X}$ & $\mathrm{X}$ & \\
\hline $\begin{array}{l}\text { Selection, } \\
\text { development } \\
\text { and review of } \\
\text { questionnaires and } \\
\text { items }\end{array}$ & $\mathrm{X}$ & $\mathrm{X}$ & $\mathrm{X}$ \\
\hline $\begin{array}{l}\text { Outlining of } \\
\text { procedures re: } \\
\begin{array}{l}\text { Selection of } \\
\text { participants and } \\
\text { confidentiality }\end{array}\end{array}$ & $\mathrm{X}$ & $\mathrm{X}$ & \\
\hline $\begin{array}{l}\text { Ethics review and } \\
\text { input }\end{array}$ & $\mathrm{X}$ & $\mathrm{X}$ & \\
\hline $\begin{array}{l}\text { Data Collection } \\
\text { Interpretation of the } \\
\text { data }\end{array}$ & $\mathrm{X}$ & $\mathrm{X}$ \\
\hline $\begin{array}{l}\text { Dissemination of } \\
\text { results }\end{array}$ & \begin{tabular}{l} 
\\
\hline $\begin{array}{l}\text { Data Analysis } \\
\text { Discussion / }\end{array}$
\end{tabular} & $\mathrm{X}$ & \\
\hline
\end{tabular}


Table 2. CPS Worker Participatory Action Research Questionnaire (N=28)

\begin{tabular}{|c|c|c|c|}
\hline (-) Not at all & \multicolumn{3}{|c|}{$(+)$ Extremely } \\
\hline Question & $\mathrm{N}$ & Mean & $\mathrm{SD}$ \\
\hline 1. How relevant to your work is this research? & 34 & 5.7 & 1.1 \\
\hline 2. How invested do you feel in this research project? & 34 & 5.7 & 1.0 \\
\hline 3. How collaborative has this project been? & 33 & 5.8 & 1.2 \\
\hline $\begin{array}{l}\text { 4. Given where you are at in your career, how much have you learned about } \\
\text { research? }\end{array}$ & 32 & 4.6 & 1.3 \\
\hline $\begin{array}{l}\text { 5. Given where you are at in your career, how much have you learned about } \\
\text { practice? }\end{array}$ & 33 & 4.4 & 1.3 \\
\hline 6. Have you felt your contributions were taken into consideration by the group? & 33 & 6.1 & 0.9 \\
\hline $\begin{array}{l}\text { 7. How supportive has your institution been about your participation in this } \\
\text { research? }\end{array}$ & 34 & 5.7 & 1.1 \\
\hline $\begin{array}{l}\text { 8. Have the group meeting minutes been accurate reflections of the group } \\
\text { discussions? }\end{array}$ & 28 & 6.3 & 0.7 \\
\hline 9. Have the group meeting minutes been helpful? & 31 & 5.8 & 0.9 \\
\hline $\begin{array}{l}\text { 10. Do you believe this project can have an impact on practice and benefit CAS } \\
\text { youth? }\end{array}$ & 33 & 6.2 & 0.7 \\
\hline 11. Please estimate the number of hours / week you devote to this project & 23 & 1.4 & 1.1 \\
\hline 12. Have you discussed this research project with your supervisor? & $96 \%-\mathrm{YES}$ & $4 \%-\mathrm{NO}$ & \\
\hline 13. Have you discussed this research project with other staff? & $94 \%-$ YES & $6 \%-\mathrm{NO}$ & \\
\hline 14. Are these discussions being updated over time? & $89 \%-\mathrm{YES}$ & $11 \%-\mathrm{NO}$ & \\
\hline 15. Is the workload for this project too heavy? & $10 \%-\mathrm{YES}$ & $90 \%-\mathrm{NO}$ & \\
\hline
\end{tabular}




\section{Child Protective Services and University-Based Partnerships}

Table 3. Pre and Post-questionnaire items - MAP Study

Response Options

Not at All

1

2

Question

1. How relaxed do you feel? $(\mathrm{N}=479)$

2. How happy do you feel? $(\mathrm{N}=479)$

3. How clear is this study to you? $(\mathrm{N}=477)$

4. How distressed do you feel? $(\mathrm{N}=476)$

5. How interested are you in this study? $(\mathrm{N}=479)$

6. How important do you think this study is? $(\mathrm{N}=475)$

7. How easy is it for you to breathe? $(\mathrm{N}=477)$

8. How tense are your muscles? $(\mathrm{N}=469)$

9. How high is your energy level? $(\mathrm{N}=474)$

10. How easy do you feel it is to express yourself? $(\mathrm{N}=473)$

11. How well do you think you could focus on things? $(\mathrm{N}=478)$

$$
* \mathrm{p}=.01 \quad * * \mathrm{p}<.001
$$

Some

4

5

$\begin{array}{lc}\text { Pre-Survey } & \text { Post-Survey } \\ \text { Mean (SD) } & \text { Mean (SD) }\end{array}$

$4.44(1.29) \quad 4.05(1.63) \quad t=5.21 * *$

$4.21(1.33)$

$3.77(1.58)$

$t=4.27 * *$

$4.91(1.21)$

$5.01(1.23)$

$1.86(1.69)$

$2.12(1.93)$

$t=-2.15 *$

$4.76(1.22)$

4.72 (1.39)

$4.84(1.26)$

$4.85(1.38)$

$5.25(1.13)$

4.83 (1.55)

$t=6.29 * *$

2.22 (1.88)

$2.46(2.02)$

$t=-2.53 *$

$3.92(1.57)$

3.44 (1.65)

$t=6.10 * *$

$4.38(1.46)$

$4.23(1.77)$

$4.46(1.20)$

$4.32(1.46)$ 